\title{
OSTEOMETRY OF FEMUR WITH ITS CLINICAL IMPLICATIONS
}

\author{
Jha $\mathbf{S}^{*}$, Chauhan $\mathbf{R}^{\star *}$ \\ ${ }^{*}$ Department of Anatomy, Heritage Institute of Medical Sciences, Varanasi, UP, India \\ ${ }^{* *}$ Department of Anatomy, University College of Medical Sciences, Delhi, India
}

\begin{abstract}
Introduction: Femur osteometry is important for establishing individual identity, designing of prosthesis for hip replacement surgeries, nail application, and determination of age and sex. Review of previous study showed a lack of extensive database. This study was undertaken to build baseline data for femur osteometry in North Indian population.
\end{abstract}

Material \& Methods: One hundred and fifteen dry human femur of undetermined age and gender were collected for this study. Parameters namely length of femur, vertical diameter of head, transverse diameter of head, epicondylar breadth and neck shaft angle were measured using a vernier calliper. Data was analysed statistically using SPSS 19 software.

Results: The mean values for length, vertical diameter head, transverse diameter head, epicondylar breadth and neck shaft angle were $418.16+27.34 \mathrm{~mm}, 38.43 \pm 3.87 \mathrm{~mm}, 35.41 \pm 3.76 \mathrm{~mm}, 72.06 \pm 6.55 \mathrm{~mm}$ and $121.5 \cong \pm 6.14$ respectively for the studied population.

Conclusion: Study signifies the importance of collecting ostemetric data of femur for a specific population due to ethnic and environmental factors affecting it.

Keywords: Femur, osteometry, vertical diameter head, transverse diameter head, epicondylar breadth, neck shaft angle.

\section{INTRODUCTION}

Femur is the strongest and longest bone of human body. A comprehensive insight into physical characteristics of bone helps forensic anthropologist to provide information on slight distinctions in human skeleton that are helpful in finding individual identity [1]. Apart from identification of an individual, it can be used for trauma analysis, photographic superimposition, and to determine time interval since death of an individual [2].

Fracture of neck of femur and hip joint dislocation is commonly seen in clinical practice. Data of diameter of the head and neck of the femur is crucial in orthopaedic surgery in prosthesis and nail application. It is required in radiology to determine age and recognise bone pathology. The femoral normative values can be used by plastic and reconstructive surgeons in their reconstruction and medical rehabilitation [3].

In forensic osteology, finding of sex from skeletal remains is of utmost value and depends largely on data techniques to give precise information. In addition, long bones either singly or jointly are used for determining sex [4].

The hard composition of femur makes it the ideal bone to be preserved for forensic examination [5].

When previous literature was reviewed, it was found that there was lack of an extensive database in North Indian population. Since the morphometric measurements vary with sex, age, race, ethnicity, climate and other geographical factors, regional variation is found in dimensions [6], hence this study 
was undertaken to study and analyse the various dimensions of femur in North Indian population.

\section{MATERIAL AND METHODS}

One hundred and fifteen (Right=58, Left=57) adult dry human femurs of unknown gender were collected from bone bank of Department of Anatomy, University College of Medical Sciences, Delhi and Heritage Institute of Medical Sciences, Varanasi. Unossified, deformed and fractured bones were excluded from the present study. Materials required for the study were osteometric board, digital vernier calliper, thread, clay, angle measuring protractor, measuring scale, tape and marker pencils

The following dimensions were measured [7]:

\section{Length of femur (ML) (Fig. $1 \mathrm{~A}$ ):}

In anatomical position, the highest point on the head was identified and marked as point $a$ and a line drawn from highest point in coronal plane wherever it cut the lower extreme articular margin of the lower end of femur was taken as point $b$. The distance between points $a$ and $b$ were measured using a measuring tape.

\section{Vertical diameter of head (VDH) (Fig. 1 B):}

The maximum diameter of head in vertical plane was measured by using a digital vernier calliper.

\section{Transverse diameter of head (TDH) (Fig. $1 \mathrm{C}$ ):}

The maximum diameter of head in transverse plane taken at right angle to vertical diameter by using a digital vernier calliper.

\section{Epicondylar breadth (ECB) (Fig. 2 A):}

The distance between the most projected points on the epicondyles was measured using a digital vernier calliper.

\section{Neck shaft angle (NSA) (Fig. 2 B):}

The angle made by axis of shaft with the axis of the upper anterior column. Axis of column is computed by using a thread which divides the anterior surface of the column in two equal halves. Axis of the shaft is computed by a thread which spreads in the mid sagittal plane over the anterior surface of the bone from the upper end of the oblique line stretching between the condyles.

Statistical analysis: The data was measured in millimetre $(\mathrm{mm})$, tabulated and analysed using SPSS
19 software. The results were compared accordingly. The level of significance was marked at $p<0.05$ at $95 \%$ confidence interval.

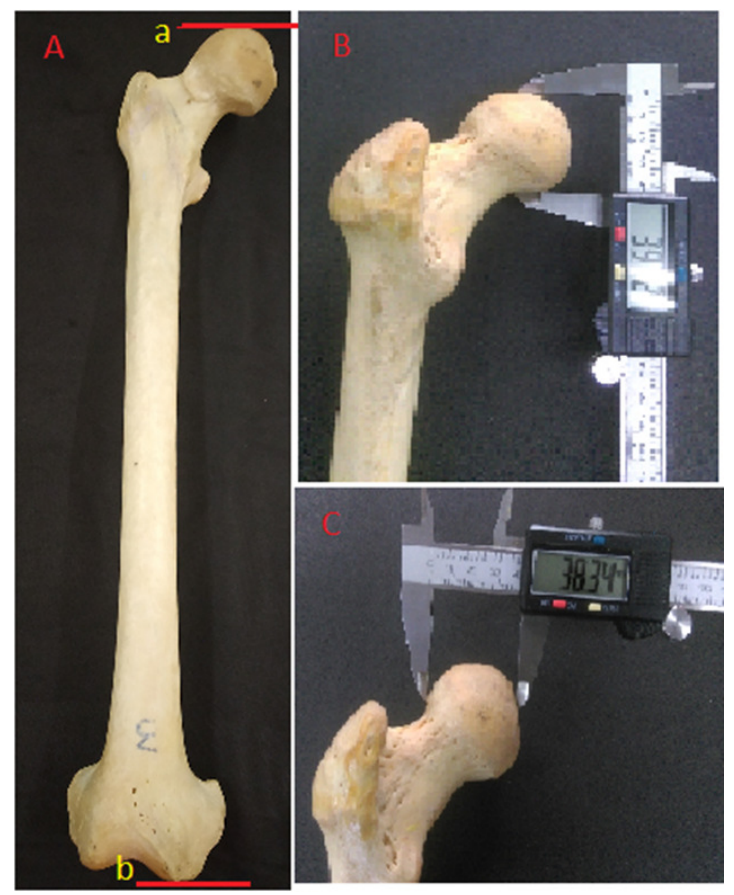

Fig 1: Photograph showing measurement of: A. Length of femur (ab), B. Vertical diameter of head, C. Transverse diameter of head

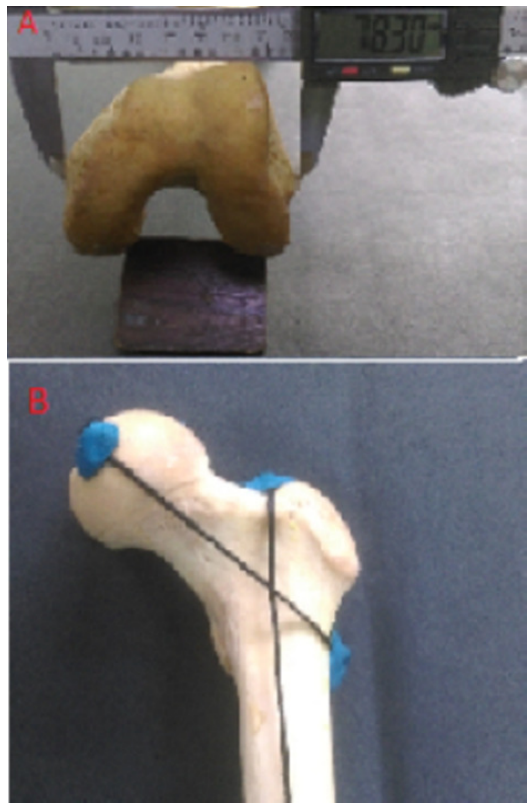

Fig 2: Photograph showing measurement of: A. Epicondylar breadth $B$. Neck Shaft angle 


\section{OBSERVATION AND RESULTS}

Average length of femur was $418.16+27.34 \mathrm{~mm}$ with mean left side length as $420.23+26 \mathrm{~mm}$ and mean right side length as $416.13+28 \mathrm{~mm}$. The average mean vertical diameter of head was $38.43 \pm 3.87 \mathrm{~mm}$, mean right transverse diameter of head was $38.17 \pm$ $3.76 \mathrm{~mm}$ and left was $38.7 \pm 4 \mathrm{mms}$ The average mean transverse diameter of head was $35.41 \pm$ $3.76 \mathrm{~mm}$, mean right transverse diameter of head was $35.53 \pm 3.68 \mathrm{~mm}$ and left was $35.37 \pm 3.83 \mathrm{mms}$. The average mean epicondylar breadth was $72.06 \pm$ $6.55 \mathrm{~mm}$ with mean right epicondylar breadth as 72.48 $\pm 6.38 \mathrm{~mm}$ and left as $71.63+6.75 \mathrm{~mm}$. The average mean neck shaft angle was $121.5 \pm 6.14^{\circ}$, mean right neck shaft angle was $119.37 \pm 4.52$ and left was 123.7 \pm 6.7 (Fig. 3 \& 4).

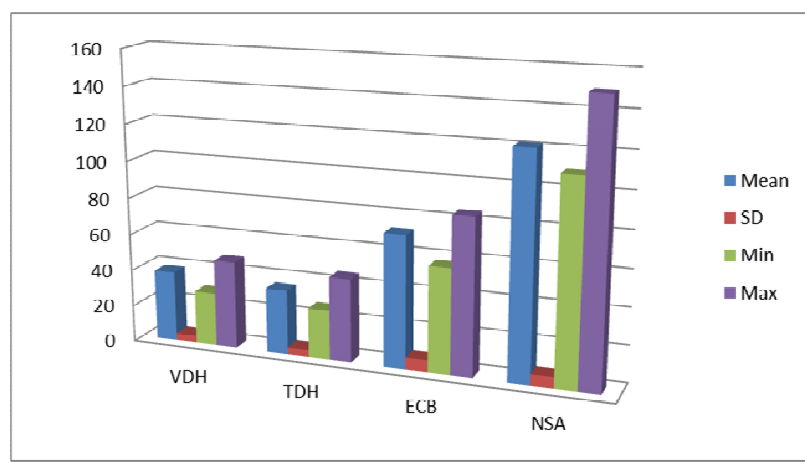

Fig. 3: Bar diagram showing mean, standard deviation, minimum and maximum values for various parameters (VDH: vertical diameter of head, TDH: transverse diameter of head, ECB: epicondylar breadth, NSA: neck shaft angle)

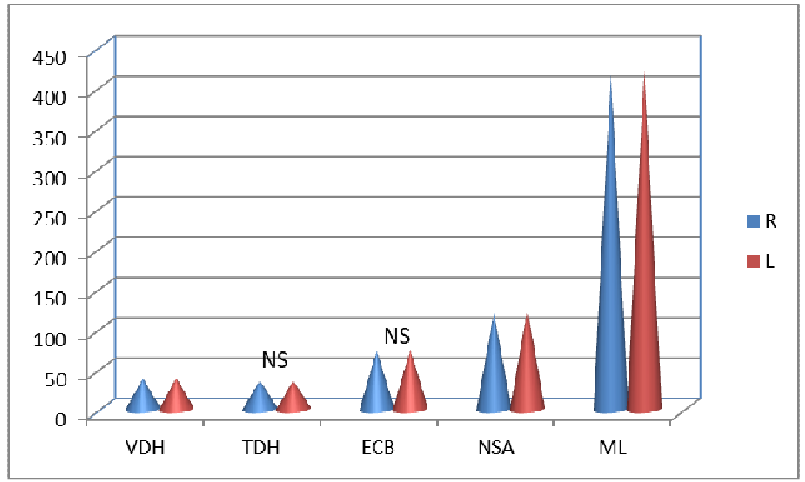

Fig. 4: Comparison of femur parameters on right and left sides

\section{DISCUSSION}

The present study was an attempt to construct data on different dimensions of adult femur in North Indian population. When osteometric data of various dimensions of femur was compared with other racial groups (Asian, African and Turkish), it was found that mean values of ML, VDH, TDH, ECB and NSA were $418.16+27.34 \mathrm{~mm}, 38.43 \pm 3.87 \mathrm{~mm}, 35.41 \pm 3.76 \mathrm{~mm}$, $72.06 \pm 6.55 \mathrm{~mm}$ and $121.5 \pm 6.14^{\circ}$ respectively in our study and were statistically significant $(p<0.05)[8-10]$ (Table 1 ).

On an average, mean value of all parameters in our study were found to be lower when compared with African, Turkish and Asian groups [8-10] (Fig. 5).

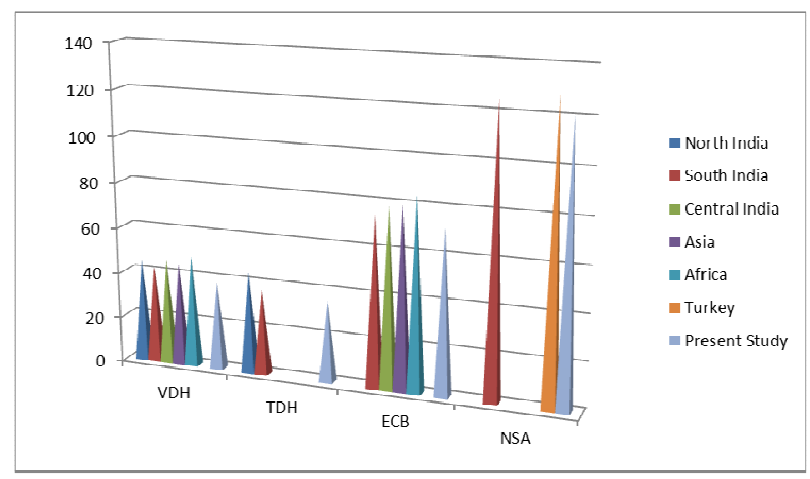

Fig. 5: Comparing mean values of various femoral parameters from across the world

Data from various Indian origin population groups were used for regional comparison. Most of the parameters like ML, VDH, ECB and NSA were variable as far as statistical significant difference was concerned [5, 11-13]. Difference was statistically significant with respect to these parameters when data from present study was compared with that from central and North Indian population. However, the difference was statistically non-significant for these parameters when compared with South Indian studies $[5,12]$ (Table 1).

VDH was the only parameter which showed statistically significant difference amongst various population groups. Both regional and racial variations were found [5, 8-13] (Table 1). The variability in this parameter should be particularly kept in mind when designing prosthesis for specific population groups to ensure better treatment outcomes.

The knowledge about different diameter of the head and neck of the femur is essential in orthopedic 
surgery in prosthesis and nail application. This is helpful in radiological practice in recognising pathology of bone and for determination of age [3].

Data of femoral head from both sexes is required for structuring of prosthesis used in hip replacement surgery [14]. Sex can determined concretely by discriminant function analysis and can be estimated by $85 \%$ accuracy in case of vertical diameter and $81.7 \%$ in case of transverse diameter $[12,15]$.
As explained above, osteometric measurement of femur can be used extensively in anatomy, forensic science, radiology, orthopedic surgery, and structuring of prosthesis of femoral head [16]. To the best of our knowledge no other Indian study has collected and analysed such an extensive database, considering the fact that our sample size was largest and several parameters were measured. This study will effectively contribute to build an elaborate baseline data for North Indian population.

Table 1: Comparison of various parameters between various population groups

\begin{tabular}{|c|c|c|c|c|c|c|}
\hline Parameter & Authors & Region & $\begin{array}{l}\text { Sample } \\
\text { number }\end{array}$ & $\begin{array}{l}\text { Mean } \\
(\mathrm{mm})\end{array}$ & 'p' value & $\begin{array}{l}\text { Significance } \\
\text { Level }\end{array}$ \\
\hline \multirow[t]{3}{*}{ Length } & Pillai et al. (2014) & India South & 50 & $437 \pm 31$ & 0.001 & NS \\
\hline & Purkait \& Chandra (2014) & India Central & 80 & $450 \pm 21$ & $<0.0001$ & $S$ \\
\hline & Steyn \& Iscan (1997) & Africa & 56 & $450 \pm 27$ & $<0.0001$ & $S$ \\
\hline \multirow{7}{*}{$\begin{array}{l}\text { Vertical Diameter } \\
\text { Head }\end{array}$} & Pillai et al. (2014) & India South & 50 & $42 \pm 3.5$ & $<0.0001$ & $S$ \\
\hline & Khaleel \& Shaik (2014) & India South & 50 & $42 \pm 3.6$ & $<0.0001$ & $S$ \\
\hline & Purkait \& Chandra (2014) & India Central & 80 & $46 \pm 2.3$ & $<0.0001$ & $S$ \\
\hline & Pandey \& Gaikwad (2016) & India North & 60 & $44 \pm 3$ & $<0.0001$ & $\mathrm{~S}$ \\
\hline & King et al. (1998) & Asia & 70 & $45 \pm 1.9$ & $<0.0001$ & $S$ \\
\hline & Steyn \& Iscan (1997 & Africa & 56 & $48 \pm 2.6$ & $<0.0001$ & $\mathrm{~S}$ \\
\hline & Atilla et al. (2007) & Turkey & 114 & $45 \pm 4.1$ & $<0.0001$ & $S$ \\
\hline \multirow{2}{*}{$\begin{array}{l}\text { Transverse } \\
\text { Diameter } \\
\text { Head }\end{array}$} & Pillai et al. (2014) & India South & 50 & $37 \pm 3$ & 0.0070 & NS \\
\hline & Pandey \& Gaikwad (2016) & India North & 60 & 44.6 & $<0.0001$ & $S$ \\
\hline \multirow{4}{*}{$\begin{array}{l}\text { Epicondylar } \\
\text { Breadth }\end{array}$} & Pillai et al. (2014) & India South & 50 & $75 \pm 6.0$ & 0.0064 & NS \\
\hline & Purkait \& Chandra (2014) & India Central & 80 & $78 \pm 4.5$ & $<0.0001$ & $S$ \\
\hline & King et al. (1998) & Asia & 70 & $78 \pm 3.5$ & $<0.0001$ & $S$ \\
\hline & Steyn \& Iscan (1997) & Africa & 56 & $84 \pm 4.6$ & $<0.0001$ & $S$ \\
\hline \multirow[t]{3}{*}{ Neck Shaft Angle } & Pillai et al. (2014) & India South & 50 & $106 \pm 6.5$ & $<0.0001$ & $S$ \\
\hline & Khaleel \& Shaik (2014) & India South & 50 & $125 \pm 6.5$ & 0.0005 & NS \\
\hline & Atilla et al. (2007) & Turkey & 114 & $128 \pm 4.7$ & $<0.0001$ & $S$ \\
\hline
\end{tabular}

\section{CONCLUSION}

This study reinforces the importance of collecting extensive database for osteometric measurements of femur for varied population groups as they get affected by ethnic and environmental factors. This is to ensure better treatment outcomes. 


\section{REFERENCES}

1. Takale S, Bagal G. Sex determination from the upper end and length of the femur: A morphometric study. JMSCR. 2016; 4 (2):9257-61.

2. Camps FE, Robinson AE, Lucas BGB, Thomas FC. G Randwohl's Legal Medicine. $3^{\text {rd }}$ ed. Bombay: K M Varghese Company; 1998:110.

3. Sembian U, Muhil M, Srimathi.T, Muthukumar T, Kumari NSD. A study of sexual dimorphism in femora of rural population of south Tamilnadu, India. JCDR. 2012; 6(2): 163-165.

4. Krogman WM, Iscan MY. Human Skeleton in Forensic Medicine. $2^{\text {nd }}$ ed. Springfield: Charles C. Thomas; 1986.

5. Pillai TJ, Lakshmi Devi CK, Sobha Devi T. Osteometric studies of human femur. IOSR J Dental Med Sci. 2014; 13(2):34-39.

6. Singh SP and Singh S. The sexing of adult femora: Demarking points for Varanasi zone. Journal of the Indian Academy of Forensic Sciences 1972 B; 11:1- 6.

7. Buikstra JE, Ubelaker DH. 1994. Standards for Data Collection from Human Skeletal Remains. Fayetteville Arkansas: Arkansas Archaeological Survey, Research Series No. 44.

8. Steyn M, Iscan MY. Sex determination from the femur and tibia in South African Whites. Forensic Sci Int. 1997; 90 (1-2):111119.
9. King CA, Iscan MY, Loth SR. Metric and comparative analysis of sexual dimorphism in the Thai femur. J Forensic Sci. 1998; 43 (5): 954-58.

10. Atilla B, Oznur A, Caglar O, Tokgozoglu M, Alpaslan M. Osteometry of the femora in Turkish individuals: a morphometric study in 114 cadaveric femora as an anatomic basis of femoral component design. Acta Orthop Traumatol Turc. 2007; 41(1):64-68.

11. Purkait $R$, Chandra $H$. A study of sexual variation in Indian femur. Forensic Sci Int. 2004; 146 (1):25-33.

12. Pandey R, Gaikwad $H$. Sex determination by discriminant function analysis of femoral heads of a North Indian population. Indian Journal of Forensic and Community Medicine. 2016; 3(3): 172-175

13. Khaleel N, Shaik HS. Osteometric study of human femur. Int J Res Med Sci. 2014; 2(1):104-107.

14. Chauhan R, Paul S, Dhaon BK. Anatomical parameters of North Indian hip joints-Cadaveric Study. J Anat Soc India. 2002; 51(1):39-42.

15. Hsiao TH, Chang HP, Liu KM. Sex determination by discriminant function analysis of lateral radiographic cepahlometry. J Forensic Sci. 1996; 41(5):792-5.

16. Shivashankarappa A, Prasad NC and Pavan PH. A study on femur neck shaft angle and its clinical importance. International Journal of Orthopaedics Sciences. 2017; 3(4): 755-757. 